\title{
Agile Challenges in Practice: A Thematic Analysis
}

\author{
Peggy Gregory ${ }^{1}$, Leonor Barroca ${ }^{2}$, Katie Taylor ${ }^{1}$, Dina Salah ${ }^{2}$, \\ Helen Sharp ${ }^{2}$ \\ ${ }^{1}$ University of Central Lancashire, Preston PR1 2HE, UK \\ 2 The Open University, Walton Hall, Milton Keynes MK7 6AA, UK \\ ajgregory, kjtaylor@uclan.ac.uk; leonor.barroca, helen.sharp, dina.salah@open.ac.uk
}

\begin{abstract}
As agile is maturing and becoming more widely adopted, it is important that researchers are aware of the challenges faced by practitioners and organisations. We undertook a thematic analysis of 193 agile challenges collected at a series of agile conferences and events during 2013 and 2014. Participants were mainly practitioners and business representatives along with some academics. The challenges were thematically analysed by separate authors, synthesised, and a list of seven themes and 27 sub-themes was agreed. Themes were Organisation, Sustainability, Culture, Teams, Scale, Value and Claims and Limitations. We compare our findings against previous attempts to identify and categorise agile challenges. While most themes have persisted we found a shift of focus towards sustainability, business engagement and transformation, as well as claims and limitations. We identify areas for further research and a need for innovative methods of conveying academic research to industry and industrial problems to academia.
\end{abstract}

Keywords: Agile Methods; Challenges: Evidence-based Software Engineering

\section{Introduction}

Successfully adopting and using agile approaches within an organisation is challenging. As agile approaches mature and their use becomes more widespread [1], the nature of the challenges that practitioners and organisations face is changing. New challenges are emerging and the focus of existing challenges is shifting, reflecting the current state of practice. Some activities that used to be regarded as challenging, for example setting up a Scrum team, are well understood, and are no longer regarded that way. There is now a growing body of research literature, experience reports, books and guidelines providing suggestions for those seeking help. Even so, some known challenges still pose problems in practice. Additionally, new challenges are emerging as organisations push the boundaries of existing techniques and try new approaches or move into unknown territory.

The Agile Research Network (ARN), www.agileresearchnetwork.org, is a collaboration between the authors' institutions and an industry body, the DSDM Consortium. We believe that in order for our research to have relevance, we need to work on problems that have been identified by practitioners. We work with organisations in the following way: we identify a relevant challenge, conduct a case study to explore the challenge within its organisational context, and conduct a literature review to identify suggested solutions. We discuss our findings with the organisation, engage in a dialogue with them about mitigation strategies and undertake research into changes made. We then publish our findings as academic papers for the research community [2-4] and as white papers for the practitioner community $[5,6]$. In order to find out what topics are most challenging for organisations, we have developed a 'Challenge Wall' (see Figure 1), deployed at five Agile Conferences and events between October 2013 and October 2014. We have used this challenge wall to collect agile challenges from a range of attendees. In this paper we report our approach and present a thematic analysis of our findings.

\section{Related Work}

A series of papers have charted the progress of agile research since its early days. In 2003 Abrahamson et al found 'a jungle of emerged software development methods', and a lack of empirical evidence to support ideas [7]. In 2008, Dingsøyr et al [8], stated that the primary challenge for agile research was to combine academic rigour with industrial relevance, suggesting that researchers could use research methods such as action research as a way to increase relevance and impact. In a systematic review in the same year, Dybå and Dingsøyr concluded that there was a need for more empirical research, and 
suggested that researchers should aim to understand the drivers of agile adoption as well as its effects [9]. The call for more research continued in 2009 by Abrahamson et al. [10], who also identified a need for more rigour and industrial studies, as well as highlighting a lack of clarity about what was meant by agility. More recently the research landscape has changed. Both Dingsøyr et al in 2012 [11] and Chuang et al in 2014 [12] have reported an increase in published research, indicating a maturing field.

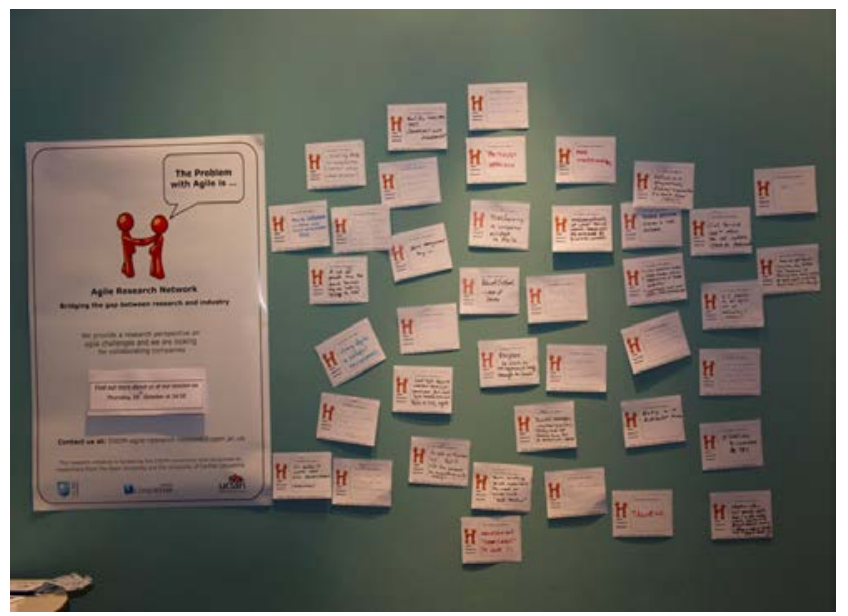

Figure 1: The Challenge Wall at ABC 2013

A number of systematic literature reviews have investigated specific topic areas within agile: by reviewing the state of research, synthesising research themes and identifying challenges. For example, a 2011 review of agile global software engineering literature [13] concluded that research was increasing but there was a predominance of industrial experience reports which report on modifications to practice based on contextual factors. A 2014 review of communication in agile global software development identified seven research themes, and reported that about half of the chosen papers were experience reports [14]. Other systematic reviews have appraised topics in agile software development such as user-centred design [15, 16], Scrum challenges in global software engineering [17], governance [18] and embedded software [19].

Research overviews and systematic literature reviews usually focus on the state of research from an academic viewpoint, although in the agile field the importance of industrial relevance and practical impact is widely acknowledged. However, academics and practitioners value different aspects of research. Academics tend to value methodological rigour and the building of theory whereas practitioners look to research to provide answers to specific practical problems and evidence to show which approaches are most effective.

A number of authors have noted the predominance of industrial experience reports in the agile literature [13, 14, 20]. Experience reports are extremely useful as they tell a coherent and contextualised story about an organisation, and in doing so describe practice, suggest practical techniques, and provide guidelines. However, one of the limitations of this type of literature is that experience reports usually tell positive stories of problems solved rather than describing persistent difficulties, worsening situations or failures. As a result they give us snapshots of successful practice, but almost certainly do not represent the state-of-the-practice. Indeed, few papers describe major unresolved problems or failures, resulting in a general publication bias towards only reporting success. Since many lessons are learnt in response to mistakes and failures, this bias, although unsurprising, is not helpful. This problem is not specific to the agile area, and has been noted in other disciplines [21].

During a panel discussion at XP2010 practitioners said that researchers did not always address questions they wanted answering. During the rest of the conference delegates were asked to suggest and vote on topics that should be researched, in order to create a prioritised list of 'burning issues' for the agile research community [22]. During an XP2013 workshop Dingsøyr and Moe elicited and ranked research challenges for large-scale agile software development [23] from a mixture of practitioners and academics. Taking this approach to identifying research questions is a more direct way of ensuring research relevance, but how relevant the challenges are to practice depends on who is suggesting the challenges.

Several attempts have been made to categorise challenges faced in the application of agile. Gandomani et al. [24] categorise the challenges faced by organisations when migrating to agile into four main categories: organisation and management; people; process; and tools related challenges. This classification is based solely on existing literature. Using grounded theory, van Waardenburg and van 
Vliet [25] investigated the challenges caused by the co-existence of agile methods and plan-driven development, and discussed mitigation strategies for those challenges. This work is based on 21 interviews with agile practitioners from two large enterprises in the Netherlands. They organised the challenges under two categories: 'increased landscape complexity' and 'lack of business involvement'. The paper exposes consequences of the former category as 'problems with communication', 'dependent definition of done', and 'difficulties to create change'. The consequences of the latter category are problems with requirements gathering, slow reaction to change, problems with requirements prioritisation and limited feedback from the business. For both challenge categories, mitigation strategies were proposed that focused on communication between the agile and traditional part of the organisation, and the communication timing.

Conboy et al [26] identified nine themes for challenges experienced by 17 large multinational organisations using agile methods. The research focused on challenges encountered by people involved in the agile development process. The themes were: developer fear as a result of the transparency of skill deficiencies; the need for developers to be "master of all trades"; dependency on social skills; deficiency of developers' business knowledge; the need to understand and learn values and principles of agile, not just the practices; lack of developer motivation to use agile methods; implications of devolved decision-making; the need for agile compliant performance evaluation; and absence of specific recruitment policies and absence of trained IT graduates for agile. Cohn and Ford [27] focused on the challenges related to the transition from plan-driven processes to agile processes and the wider impact of this transition not only on the development team members, but also on management, other departments, and other agile teams. They proposed several approaches for introducing agile to organisations. These focused on recommendations related to the different roles and factors impacting the transition to agile.

\section{Method}

The ARN deployed a 'Challenge Wall' at five Agile Conferences and events between October 2013 and October 2014. This section discusses the challenges collected and how they were analysed.

\subsection{Data Collection}

When we ran a challenge wall we positioned an ARN poster in a visible place in the conference or event venue and provided a stack of pens and small cards on which each challenge was written. Delegates were encouraged to fill out the cards anonymously (see Figure 2), and these were then attached to the wall next to the poster for others to read. Delegates wrote one challenge per card, and could fill in as many cards as they wished. The challenge wall gradually grew throughout the event, and became a trigger for discussions between delegates and the ARN team about the nature and context of the challenges identified. After each event the cards were removed from the wall and the contents were typed up into a spreadsheet.

The first agile challenge wall was set up at the Agile Business Conference in 2013. We soon realised that we had uncovered a powerful way of identifying issues of concern. As a result, we subsequently ran the challenge wall at several agile events in order to build up a larger set of data for analysis.

We collected challenges using the challenge wall at five different events during 2013 and 2014. These events were: the Agile Business Conference, London, October 2013 (www.agileconference.org); DSDM Members Day, Manchester, November 2013 (www.dsdm.org); XP, Rome, May 2014 (www.xp2014.org); AgileNorth, Preston, June 2014 (www.agilenorth.org); and the Agile Business Conference, London, October 2014 (www.agileconference.org).

\subsection{Participants}

The attendees at the five events were mostly agile practitioners and business representatives rather than academics, except for the XP Conference in 2014 that was attended by a mixture of practitioners and academics. Practitioner and business attendees represented a range of organisational roles. An analysis of attendance data from the 2014 ABC Conference (the only event about which we had access to such data), showed that $34 \%$ of attendees were managers, $14 \%$ were from business roles, $12 \%$ were executive-level managers, $12 \%$ were developers, $8 \%$ were consultants, $8 \%$ were project managers, $5 \%$ 
were analysts, 3\% were coaches and $4 \%$ were from other roles (including some students and academics). It is likely that ABC 2013 and the DSDM Members day had a similar mix of attendees.

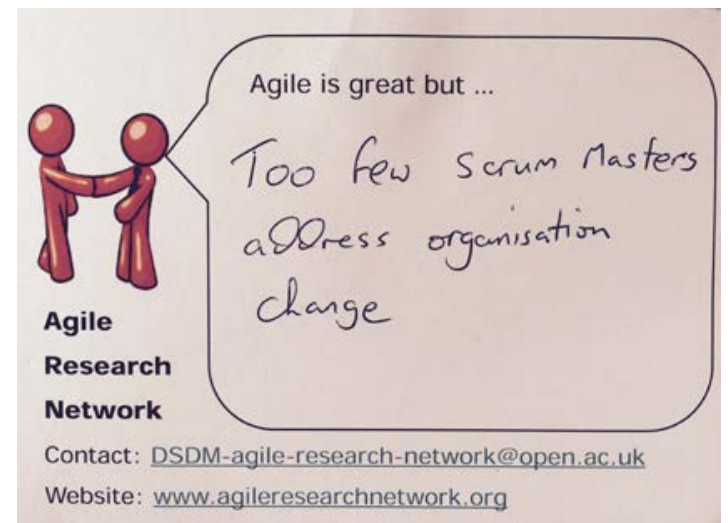

Figure 2: A Challenge Card

\subsection{Data Analysis}

We used a thematic analysis approach for data analysis. This is a data synthesis method that identifies, analyses and reports patterns (themes) within data. It describes and organises the data set in rich detail and interprets different aspects related to the research topic [28]. The data is first labeled and coded, and those codes are then inspected resulting in some relabeling, dropping and merging of codes. Finally, codes are translated into themes.

Three of the authors, Salah, Gregory and Barroca each completed an independent thematic analysis of the challenges, then Taylor and Sharp, reviewed these. They verbally clarified the meaning of the descriptors used by the other authors, and created a new spreadsheet with a merged list of sub-themes. Merging started by looking at sub-theme names and their associated challenges, and went on to identify high-level themes, which were used as grouping mechanisms for the more detailed sub-themes. Discussion focussed on whether to merge or split sub-themes, finding appropriate names for subthemes, and identifying broad themes at the right level of granularity. For example, 'culture' and 'changing mindsets/culture' had been identified as sub-themes by two of the independent analysts, but a distinction between organisational culture and national culture had not been made, so the reviewers created these as themes. They regrouped the data into nine themes and 27 sub-themes. This set of themes was revised again through discussions between all authors using Skype calls and emails, and the final set of seven themes and 27 sub-themes was agreed. For example, through group discussion at this final stage it was decided that 'organisational culture' and 'national culture' would be more appropriate as sub-themes grouped under the broader theme of 'Culture'.

\section{Results}

We collected 194 challenge cards, of which one was disregarded as inappropriate. As a result of the thematic analysis described in Section 3.3 the remaining 193 challenges determined the seven themes and 27 sub-themes. Table 1 below shows the themes and sub-themes along with a description and an example challenge from each sub-theme. The table is ordered, largest first, by the number of challenges in the themes and sub-themes, with the number of challenges in each group provided in brackets. 
Table 1: Themes and Sub-Themes identified from our Challenge Cards

\begin{tabular}{|c|c|c|c|c|}
\hline & Main Theme & Sub Themes & Description of Sub Themes & Example Challenge \\
\hline \multirow[t]{4}{*}{1} & \multirow[t]{4}{*}{$\begin{array}{l}\text { Claims and } \\
\text { Limitations } \\
(\mathrm{n}=46)\end{array}$} & $\begin{array}{l}\text { Misconceptions } \\
(\mathrm{n}=23)\end{array}$ & $\begin{array}{l}\text { The multi-faceted aspects of agile are open to many } \\
\text { different interpretations }\end{array}$ & $\begin{array}{l}\text { "Shallow Adoption" where practices or processes are } \\
\text { followed mechanically without deep insight into underlying } \\
\text { values }\end{array}$ \\
\hline & & $\begin{array}{l}\text { Shortcomings } \\
(\mathrm{n}=14)\end{array}$ & $\begin{array}{l}\text { Areas where information is sparse, limited or where } \\
\text { methods are used inappropriately }\end{array}$ & $\begin{array}{l}\text { Credibility in areas it has not traditionally used (e.g. public } \\
\text { sector) }\end{array}$ \\
\hline & & $\begin{array}{l}\text { Hype } \\
(\mathrm{n}=8)\end{array}$ & Misleading or excessive claims about agile approaches & $\begin{array}{l}\text { It's become a buzzword and as such threatening its own } \\
\text { existence. It has to be implemented thoroughly and } \\
\text { comprehensively to get great outcomes }\end{array}$ \\
\hline & & $\begin{array}{l}\text { Failure } \\
(\mathrm{n}=1)\end{array}$ & Only limited evidence is available about failures & $\begin{array}{l}\text { Some believe it to be a "silver bullet" to their problems, only } \\
\text { to realise and not like that it just exposes their existing issues }\end{array}$ \\
\hline \multirow[t]{6}{*}{2} & \multirow[t]{6}{*}{$\begin{array}{l}\text { Organisation } \\
(\mathrm{n}=45)\end{array}$} & $\begin{array}{l}\text { Business \& IT } \\
\text { transformation }(\mathrm{n}=11)\end{array}$ & $\begin{array}{l}\text { Requires business and IT to collaborate to establish } \\
\text { agility throughout the entire value chain }\end{array}$ & $\begin{array}{l}\text { It's still seen as an IT methodology. It needs the business } \\
\text { teams to buy into it and join the party }\end{array}$ \\
\hline & & $\begin{array}{l}\text { Management buy-in } \\
\& \text { understanding } \\
(\mathrm{n}=11)\end{array}$ & $\begin{array}{l}\text { Traditional management may see agile as just another IT } \\
\text { method that can be implemented and structured to 'fit' } \\
\text { existing organisational norms }\end{array}$ & $\begin{array}{l}\text { Misconceptions of what 'agile' means. Perceived as quicker } \\
\text { by business owners }\end{array}$ \\
\hline & & $\begin{array}{l}\text { Agile in a non-agile } \\
\text { environment } \\
(\mathrm{n}=10)\end{array}$ & $\begin{array}{l}\text { Teams successfully adopt agile but operate in an } \\
\text { environment where wider organisational structures are } \\
\text { more traditional }\end{array}$ & IT is agile but most of the business are not \\
\hline & & $\begin{array}{l}\text { Commitment/ } \\
\text { Engagement }(\mathrm{n}=10)\end{array}$ & $\begin{array}{l}\text { Success can be challenged by lack of awareness or } \\
\text { commitment from other stakeholders }\end{array}$ & $\begin{array}{l}\text { It only works if all stakeholders get involved and support the } \\
\text { agile process }\end{array}$ \\
\hline & & $\begin{array}{l}\text { Adoption } \\
(\mathrm{n}=5)\end{array}$ & $\begin{array}{l}\text { Concerns around 'how to' introduce agile ways of working } \\
\text { either into teams or into the wider organisation }\end{array}$ & What is the holistic business case to move to agile? \\
\hline & & $\begin{array}{l}\text { Fear } \\
(\mathrm{n}=2)\end{array}$ & $\begin{array}{l}\text { Fear of change and the unknown as agile appears less } \\
\text { structured with people 'doing their own thing' whilst using } \\
\text { a whole new set of jargon }\end{array}$ & $\begin{array}{l}\text { Traditional practitioners may fear and resist the change } \\
\text { given control moves to the team (self- organising teams) }\end{array}$ \\
\hline \multirow[t]{3}{*}{3} & \multirow[t]{3}{*}{$\begin{array}{l}\text { Culture } \\
(\mathrm{n}=31)\end{array}$} & $\begin{array}{l}\text { Organisational culture } \\
(\mathrm{n}=13)\end{array}$ & $\begin{array}{l}\text { The organisation requires a philosophical belief in people } \\
\text { over process }\end{array}$ & $\begin{array}{l}\text { Changing from a command and control/mechanistic } \\
\text { worldview to a future of autonomous, self-managed agents in } \\
\text { a systemic organisation is too much if the system does not } \\
\text { change itself-including leaders }\end{array}$ \\
\hline & & $\begin{array}{l}\text { Changing mindsets } \\
(\mathrm{n}=8)\end{array}$ & $\begin{array}{l}\text { Agile is more than a set of practices used by IT requiring } \\
\text { wide ranging change to work patterns }\end{array}$ & $\begin{array}{l}\text { It's a mind set not a methodology. Without a change in mind } \\
\text { set the result will not be met }\end{array}$ \\
\hline & & $\begin{array}{l}\text { National culture } \\
(\mathrm{n}=5)\end{array}$ & $\begin{array}{l}\text { Differences in national culture, particularly between East } \\
\text { and West, compound issues with organisational culture }\end{array}$ & Is it possible to do agile with all nationalities and cultures? \\
\hline
\end{tabular}




\begin{tabular}{|c|c|c|c|c|}
\hline & \multirow[t]{2}{*}{ Culture contd. } & $\begin{array}{l}\text { Distributed teams } \\
(\mathrm{n}=5)\end{array}$ & $\begin{array}{l}\text { Business realities are often contrary to the agile need for } \\
\text { co-located teams, with teams distributed across the UK, } \\
\text { Europe or worldwide }\end{array}$ & $\begin{array}{l}\text { It requires co-location in a digital world, where travel is too } \\
\text { expensive }\end{array}$ \\
\hline & & Trust $(\mathrm{n}=1)$ & Providing a safe environment to develop and innovate & What is the cost for not investing in trust? \\
\hline \multirow[t]{3}{*}{4} & \multirow[t]{4}{*}{$\begin{array}{l}\text { Teams } \\
(\mathrm{n}=24)\end{array}$} & $\begin{array}{l}\text { Team practices } \\
(\mathrm{n}=11)\end{array}$ & $\begin{array}{l}\text { Uncertainty and perhaps lack of training in specific } \\
\text { practices or techniques }\end{array}$ & $\begin{array}{l}\text { How to estimate/ better estimate the effort to support } \\
\text { planning? }\end{array}$ \\
\hline & & $\begin{array}{l}\text { Leadership } \\
(\mathrm{n}=5)\end{array}$ & $\begin{array}{l}\text { Traditional project management approaches of 'command } \\
\text { and control' need to be replaced by a facilitation style of } \\
\text { leadership }\end{array}$ & That the manifesto lacks Leadership over Management \\
\hline & & $\begin{array}{l}\text { Finding good people } \\
(\mathrm{n}=4)\end{array}$ & $\begin{array}{l}\text { Agile requires skilled, self-directed and motivated team } \\
\text { players }\end{array}$ & $\begin{array}{l}\text { Getting the right people interested- decision makers and } \\
\text { users }\end{array}$ \\
\hline & & $\begin{array}{l}\text { Individual motivation } \\
(\mathrm{n}=4)\end{array}$ & $\begin{array}{l}\text { Agile philosophies are often at odds with organisational } \\
\text { reward structures that value individuals }\end{array}$ & It sometimes marginalises lonely problem solvers \\
\hline \multirow[t]{4}{*}{5} & \multirow[t]{4}{*}{$\begin{array}{l}\text { Sustainability } \\
(\mathrm{n}=23)\end{array}$} & $\begin{array}{l}\text { Process improvement } \\
(\mathrm{n}=15)\end{array}$ & $\begin{array}{l}\text { Once adopted, agile requires on-going change and } \\
\text { commitment in order to become sustainable and } \\
\text { embedded within teams and the organisation }\end{array}$ & $\begin{array}{l}\text { If it is codified it becomes "bureaucratic" and if not it is too } \\
\text { diverse to be taken seriously }\end{array}$ \\
\hline & & $\begin{array}{l}\text { Documentation } \\
(\mathrm{n}=4)\end{array}$ & $\begin{array}{l}\text { Tensions arise when management sees documentation as } \\
\text { a way to demonstrate control whilst developers focus on } \\
\text { code over documents }\end{array}$ & $\begin{array}{l}\text { That it has become an excuse not to do any documentation } \\
\text { or planning beyond the sprint and product backlog }\end{array}$ \\
\hline & & $\begin{array}{l}\text { Contracts } \\
(\mathrm{n}=3)\end{array}$ & $\begin{array}{l}\text { Standard contracts require detailed upfront specifications } \\
\text { that are contrary to the evolving approach of agile }\end{array}$ & Some think they need a contract \\
\hline & & $\begin{array}{l}\text { Knowledge sharing } \\
(\mathrm{n}=1)\end{array}$ & $\begin{array}{l}\text { Needs a positive learning environment to motivate } \\
\text { individual commitment in order to establish effective } \\
\text { knowledge sharing }\end{array}$ & We innovate but we don't really share innovations \\
\hline \multirow[t]{2}{*}{6} & \multirow[t]{2}{*}{$\begin{array}{l}\text { Scaling } \\
(\mathrm{n}=15)\end{array}$} & $\begin{array}{l}\text { Large projects } \\
(\mathrm{n}=10)\end{array}$ & $\begin{array}{l}\text { Working at programme level where team practices need to } \\
\text { scale across multiple teams in large complex projects }\end{array}$ & $\begin{array}{l}\text { Agility in large projects effecting several applications, } \\
\text { platforms, techniques }\end{array}$ \\
\hline & & $\begin{array}{l}\text { Governance } \\
(\mathrm{n}=5)\end{array}$ & $\begin{array}{l}\text { Traditional mechanisms that ensure projects achieve } \\
\text { regulatory or legal compliance are often process driven } \\
\text { and bureaucratic }\end{array}$ & $\begin{array}{l}\text { Have not yet found any clear view on how the 'governance' } \\
\text { at Business Case level works or could work in relation to } \\
\text { outcomes, costs and benefits }\end{array}$ \\
\hline \multirow[t]{2}{*}{7} & \multirow[t]{2}{*}{$\begin{array}{l}\text { Value } \\
(\mathrm{n}=7)\end{array}$} & $\begin{array}{l}\text { Business value } \\
(\mathrm{n}=4)\end{array}$ & $\begin{array}{l}\text { To counter criticism of waterfall approaches where } \\
\text { organisations tended to focus on process rather than } \\
\text { product, agile projects must demonstrate value }\end{array}$ & Ensuring that projected value is achieved \\
\hline & & $\begin{array}{l}\text { Measurement } \\
(\mathrm{n}=3)\end{array}$ & $\begin{array}{l}\text { Many organisation use wide ranging metrics but these are } \\
\text { not always appropriate or necessary to agile projects }\end{array}$ & $\begin{array}{l}\text { The lack of well formulated and defined measurement } \\
\text { practices }\end{array}$ \\
\hline
\end{tabular}




\section{Discussion}

Research interest in agile has been growing steadily as indicated by the publication of over 200 peerreviewed journal articles in the period between 2001 and 2012 [12]. Amongst these many publications we have seen: a systematic literature review identifying the areas being researched [9]; a prioritisation of research needed in the form of a preliminary roadmap [8]; and a prioritised list of the areas of research that practitioners would like to see addressed [22].

Here we discuss how the challenges we have gathered are related to previous literature reviews in the area. First we compare our themes and sub-themes with areas identified in Dybå and Dingsøyr's 2008 systematic literature review [9] and investigate research on specific sub-themes by undertaking a title search of the papers listed by Chuang et al [12] in their 2014 systematic literature review (section 5.1). Second, we compare our findings with the research areas Dingsøyr et al [8] established as goals for research achievements by 2015 (section 5.2). Third, we discuss how practitioner concerns have evolved over time by comparing the challenges we have collected with those collected at XP2010 by Freudenberg and Sharp [22] (section 5.3). Finally we discuss the limitations of our approach (section 5.4). All italicised quotes in this section are verbatim transcriptions from challenge cards.

\subsection{Are these challenges reflected in research literature?}

The seven themes and 27 sub-themes identified in our challenge set represent a mix of familiar and less familiar topics found in the literature.

Table 2. Comparison of our themes and sub-themes with Dybå and Dingsøyr's topics [9]*

\begin{tabular}{lll}
\hline Dybå and Dingsøyr topics & Themes from this study & Sub-themes from this study \\
\hline Introduction and adoption & & \\
\hline Introduction and adoption & Organisation & Adoption \\
\hline Development process & & (Not mentioned in our challenge list) \\
\hline Knowledge and project & Sustainability & Knowledge sharing
\end{tabular}

management

\begin{tabular}{lll}
\hline Human and social factors & & \\
\hline Organisational culture & Culture & Organisational culture \\
\hline Collaborative work & Teams & Team practices \\
\hline Team characteristics & Teams & Finding good people \\
\hline Perceptions of agile & & \\
\hline Customer perceptions & Organisation & Commitment/engagement \\
\hline Developer perceptions & Teams & Individual motivation \\
& Organisation & Adoption \\
\hline Student perceptions & & (Not mentioned in our challenge list) \\
\hline Comparative studies & & \\
\hline Project management & Organisation & $\begin{array}{l}\text { Management buy-in and understanding } \\
\text { Process improvement }\end{array}$ \\
\hline Productivity & Sustainability & Process Improvement \\
\hline Product quality & Sustainability & (Not mentioned in our challenge list) \\
\hline Work practices and job & & Team practices \\
satisfaction & Teams & \\
\hline * Dybå and Dingsøyr identify four topic groups and 13 topics, which we map to four of our themes and nine of our sub-themes.
\end{tabular}

Of the familiar topics, Organisation, Sustainability, Culture and Teams are themes that have been subjects of research interest for some time. For example the topic groupings identified in Dybå and Dingsøyr's systematic review [9] are reflected in these four themes from our challenge set (Table 2).

However some sub-themes within these four main themes, such as Business and IT transformation, Fear, Contracts, Documentation and Leadership, do not seem very evident in the literature searches we have conducted for our industrial partners. This would, however, need to be confirmed by a more upto-date systematic literature review. The need for business as well as IT transformation, was of particular concern in our challenge set, with 11 challenge cards identifying this topic. Examples of challenges identified included: 
'Its take up outside of the delivery function. That it is has been coined by IT for IT without the business guys. Which organisational changes are triggered by IT without anybody noticing/caring/managing those changes?'; and

'That everyone seems to think that it starts and stops in software development. How other disciplines blend in is a big challenge'.

Scaling is also a topic that has been written about and discussed by practitioners [29, 30]. Through a title search of Chuang et al [12] we found seven papers on scaling, including large or complex projects (searching on 'scale', 'large', 'complex') and none on governance (searching on 'governance', 'PMO'). Dingsøyr and Moe reported from an XP2013 Workshop at which research challenges in largescale agile development were discussed, that there were few research studies on the topic [23]. A recent systematic literature review on agile governance, identified a small but growing research base [18].

The two themes Value, and Claims and Limitations identified in our challenge set are generally less commonly reported in the empirical research literature, although some of the associated sub-themes are more researched. In a title search of Chuang et al [12] we found no papers on the topic of business value (searching on 'value'); eight discussing measurement ('metrics', 'measurement'); and none on claims or limitations ('misconception', 'shortcoming', 'fail', 'hype', 'lack', 'claim', 'limitation').

Our participants identified 46 challenges on the theme of Claims and Limitations. Comments indicate a certain amount of frustration, but range over a number of topics, including:

'Religious approach';

'Everyone wants to reinvent it';

'Throwing away some of the old useful ideas'; and

'The lack of a project management framework for coordinating multiple teams and or work.'

While there is some literature about the concept of agility [31, 32], there is very little about misconceptions, hype and failure.

Agile hype is discussed by Janes and Succi [33] who suggest agile has followed the Gartner Hype Cycle, and is stuck in the 'Trough of Disillusionment' as a result of what they call the 'guru phenomenon'. In a grounded theory study of agile practitioners Hoda et al [34] identify agile hype and scepticism as factors that negatively affected customer involvement in agile projects. There are some discussions in the consultant literature [35], however we could find no empirical research that specifically focussed on investigating this topic.

Additionally there is very little research into agile failure. McAvoy and Butler [36] report the failure of a team to adopt an agile method, identifying ineffective decision-making and actions, which occurred as a result of the team's desire to become more cohesive, as one of the key drivers of the failure. This is a gap, and has been mentioned by other researchers [12]. It is somewhat surprising as anecdotally it is not uncommon to hear stories of failure and organisational abandonment of agile.

\subsection{Challenges and the goals set for 2015}

Dingsøyr et al in their preliminary roadmap [8] assess the state of agile research in 2008 and suggest a goal for agile research for 2015. They indicate some areas for priority in research: maturity, coverage, understanding and impact. They assess that research was having little impact on everyday practice in industry and suggest that "increased application of research methods like action research [37] can be helpful ensuring the relevance, and help provide a larger body of knowledge that can lead to a broader impact on industry."

Research has been growing significantly [12], action research is being used [2, 38] and research may be getting more relevant and is definitely increasing the body of knowledge. However, some perspectives from our challenge list are:

'That there is no academic research supporting the claimed success'; and,

'It is isolated from many fields, e.g., a good research could be about bringing information visualisation theory and methods into agile project management in a systematic way.'

This suggests that even if research has been done, the gap between research and what industry wants to know has not yet been bridged.

\subsection{Persistence of challenges over time}

We discuss how Freudenberg and Sharp's [22] top ten research questions from practitioners feature in our challenge set; we start by looking at those that persist. 
'Agile and large projects' was the top research question in the 2010 paper. Scaling is still a theme for our challenges, not only in terms of large projects:

'How do you scale up to a large project over many months or even years?';

but also in relation to complexity and the size of the organisation:

'Scaling due to complexity (rather than large projects)'; and

'Scaling across a large enterprise/companies.'

Table 3. Comparison of our themes with practitioners' top ten research questions from [22]

\begin{tabular}{ll}
\hline Freudenberg and Sharp top ten research questions & Themes/Sub-themes \\
\hline 1. Agile and large projects & Scaling \\
\hline 2. What factors can break self-organization? & Culture/Organisational culture \\
\hline $\begin{array}{l}\text { 3. Do teams really need to always be collocated to } \\
\text { collaborate effectively? }\end{array}$ & Culture/Distributed teams \\
\hline $\begin{array}{l}\text { 4. Architecture and agile-how much design is enough } \\
\text { for different classes of problem? }\end{array}$ & Scaling/Large projects \\
\hline $\begin{array}{l}\text { 5. Hard facts on costs of distribution (in \$,£,€ and so on) } \\
\text { 6. The correlation between release length and success } \\
\text { rate }\end{array}$ & $\begin{array}{l}\text { Claims and Limitations/Shortcomings } \\
\text { Sustainability/Process Improvement }\end{array}$ \\
\hline $\begin{array}{l}\text { 7. What metrics can we use with minimal side effects? } \\
\text { 8. Distributed agile and trust-what happens around 8- } \\
\text { 12 weeks? }\end{array}$ & Value/Measurement \\
\hline $\begin{array}{l}\text { 9. Statistics and data about how much money/time is } \\
\text { saved by agile }\end{array}$ & $\begin{array}{l}\text { (Time mentioned in several challenges } \\
\text { from different themes) }\end{array}$ \\
\hline $\begin{array}{l}\text { 10. Sociological studies-what were the personalities in } \\
\text { successful/failed agile teams? }\end{array}$ & Teams/ Finding good people \\
\hline
\end{tabular}

Collocation and distribution appeared in 2010 related to: effective work e.g. 'Do teams really need to always be collocated to collaborate effectively?'; cost e.g. 'Hard facts on costs of distribution (in \$, $£$, $€$, and so on)'; and trust e.g. 'Distributed agile and trust—what happens around 8-12 weeks?'.

Distributed teams appear in our challenges as a sub-theme still raising the issue of trust:

'Why does trust decline if people are not meeting in person for more than 12 weeks?'

and, to a lesser extent, the issue of cost (travel cost in one single challenge):

'It requires co-location in a digital world, where travel is too expensive'.

However, distributed teams no longer seem to raise challenges of effective collaboration. This may suggest that distributed teams are an accepted reality that has to be dealt with rather than opposed.

Trust appears today under new contexts, not limited to distributed teams:

'What is the cost for not investing in trust?'

One other research question that persists is that of metrics - 'What metrics can we use with minimal side-effects?' The Value theme gathers challenges not so much related to side effects but rather to what management wants and how to measure value:

'Agile is about measuring value, but management want efficiency, defect metrics etc.

How to demonstrate team is efficient and improving efficiency?';

'Can be difficult to define a value metric'; and

'The lack of well formulated and defined measurement practices.'

These challenges suggest a wider concern of agile within a large traditional enterprise, as agile is becoming more established and having to cohabit with more or less hostile environments.

Some research questions do still appear as challenges, but with less frequency and emphasis. That is the case of 'What factors can break self-organisation?':

'Changing from a command and control/mechanistic worldview to a future of

autonomous, self-managed agents in a systemic organisation is too much if the

system does not change itself - including leaders.'

The concern here seems also to be more about the context of the organisation rather than the internal functioning of agile teams.

Also of less importance are the issues of more detailed agile practice such as 'Architecture and agile-how much design is enough for different classes of problem?' with one single mention of architecture:

'Dealing with emergent architecture which can be $F^{*}$ agile!'

Two other research issues appear only in one or two challenges. One is 'The correlation between release length and success rate' with the two following challenges: 
'Cost of release, cannot release code easily'; and

'Agile on aged technology, environment stacks -> prevents early release to test and promotes waterfall of dev handing over to test period.'

The other is 'Sociological studies—what were the personalities in successful/failed agile teams?' with a single challenge mentioning personality:

'Would like to understand the personality type of a coach in order to make better hiring decisions.'

For the remaining research question - 'Statistics and data about how much money/time is saved by agile.' - we didn't encounter any mention of quantifying savings in time and cost. There are, however, several challenges mentioning the time it takes for agile to get established:

'It takes practice and time so needs some serious commitment';

'It is geriatric time to innovate';

'It takes practice and time so needs some serious commitment';

'Business managers only hearing on time delivery and not putting time in to deliver/write stories'; and

'I have been on a two day course. It is common scene, I am an expert. You are not. It

takes time and experience'.

The discussion above suggests that the concerns of practitioners now are less about moving into agile, or about how to do agile, but rather about sustaining agile. Agile is here to stay, sometimes in environments that are not always supportive, but within which agile development needs to coexist.

\subsection{Limitations}

Collecting challenges at these agile events was opportunistic. As a result the data cannot be seen as fully representative of the community of agile practitioners. The challenge cards were filled in anonymously so we cannot link each one with a particular job role. We had conversations with a majority of respondents and although some cards may have been completed by academics, practitioners completed most. Most of the data comes from the UK, apart from that collected at the XP Conference in Rome.

We are aware of some limitations in our comparison of themes from our data with those found in previous literature. The Dybå and Dingsøyr systematic literature review [9] is now six years old and reviewed publications up to and including 2005. Although the Chuang et al [12] systematic literature review is recent, there is no thematic topic review in the paper, so we were not fully able to compare our findings with those and had to rely on a review of titles. We believe, however, that these limitations rather than invalidating some of the suggestions made in the discussion, point to a need for more updated research in some areas.

\section{Conclusions}

If research is to have real impact in the practitioner community, researchers need to understand and address the challenges that this community faces. However, it is not simply a matter of identifying challenges and setting up research programmes to address them. The landscape of practitioner challenges is complex and multi-faceted, and while some challenge areas have persisted for many years, some have evolved, and others are new.

Through its mission to bridge the gap between industry and academia, the ARN has collected 193 challenges at practitioner-focused events during 2013 and 2014 and analysed them. This analysis allows us to make four observations:

1. Some challenges areas have persisted for many years, and are just hard to address successfully. These challenge areas would benefit from further research. For example, identifying and measuring agile value, and understanding cultural change are highly contextual and complex.

2. Some challenge areas appear to have persisted for many years, but our analysis shows that the focus of the challenge has in fact shifted. For example, concerns around scaling and distributed teams have changed. The agile field is maturing, and practitioners are less concerned about adopting agile and more concerned about sustaining agile. Research in these areas needs to have a specific and relevant focus.

3. Some challenge areas have not been widely researched. These areas include: sustainability, governance, business engagement and transformation, failure, and the impact of claims and limitations. Future research would be beneficial in some of these areas, but it is not the answer to 
all of them as some would best be addressed by further or different education and training - e.g. those challenges classified as misconceptions and hype.

4. Some challenge areas have been addressed by research but practitioners still see them as a challenge. Although research is being done, it is still not having the expected impact. This means that either practitioners are not aware of this work and it needs further dissemination, or the research is not ready for practitioner implementation.

The observations above point both to the need for further research and for improvements in knowledge transfer. The ARN addresses the latter by developing more innovative methods of conveying academic research to industry and industrial problems to academia, bridging the gap between research and practice. We have developed a model of collaboration [39] where researchers engage with collaborators in an in-depth way, spending time in the organisation to understand the context, and suggesting alternative ways of working. This promotes the transfer of knowledge in a way that takes into account the context of each organisation individually, and requires an in-depth knowledge of existing research. This approach also generates opportunities to contribute to further research based on the data generated in the collaborations.

\section{Acknowledgements}

We would like to thank all those who contributed to our challenge walls and to DSDM Consortium for supporting the Agile Research Network.

\section{References}

1. D. West: Water-Scrum-Fall is the Reality of Agile for most Organizations Today, in, Forrester Research Report, http://www.cohaa.org/content/sites/default/files/water-scrum-fall_0.pdf, (2011)

2. P. Gregory, L. Plonka, H. Sharp, K. Taylor: Bridging the Gap between Research and Practice: The Agile Research Network, in: European Conference on Research Methods, London, UK, (2014)

3. H. Sharp, L. Plonka, K.J. Taylor, P. Gregory: Overcoming Challenges in Collaboration between Research and Practice, in: Proceedings of the International Workshop on Software Engineering Research and Industrial Practices at ICSE 2014, Hyderabad, India, pp. 10-13 (2014)

4. L. Plonka, H. Sharp, P. Gregory, K. Taylor: UX Design in Agile: A DSDM Case Study, in: Agile Processes in Software Engineering and Extreme Programming, Springer International Publishing, pp. $1-15(2014)$

5. The Agile Research Network, LShift: Integrating UX Design into a DSDM Project: Challenges, Working Practices and Lessons Learned, in: http://agileresearchnetwork.org/publications/, (2013)

6. The Agile Research Network: Agile Projects in a Non-agile Environment: What is Your Experience?, in: http://agileresearchnetwork.org/publications/, (2014)

7. P. Abrahamsson, J. Warsta, M.T. Siponen, J. Ronkainen: New Directions on Agile Methods: A Comparative Analysis, in: International Conference on Software Engineering, IEEE, Portland, Oregon USA, (2003)

8. T. Dingsøyr, T. Dybå, P. Abrahamsson: A Preliminary Roadmap for Empirical Research on Agile Software Development, in: Proceedings of AGILE, IEEE, Toronto, Canada, pp. 83-94 (2008)

9. T. Dybå, T. Dingsøyr: Empirical Studies of Agile Software Development: A Systematic Review, Information and Software Technology, 50 833-859 (2008)

10. P. Abrahamsson, K. Conboy, X. Wang: "Lots Done, More To Do": The Current State of Agile Systems Development Research, European Journal of Information Systems, 18 281-284 (2009)

11. T. Dingsøyr, S. Nerur, V. Balijepally, N.B. Moe: A Decade of Agile Methodologies: Towards Explaining Agile Software Development, The Journal of Systems and Software, 82 1213-1221 (2012)

12. S. Chuang, T. Luor, H. Lu: Assessment of Institutions, Scholars, and Contributions on Agile Software Development (2001-2012), Journal of Systems and Software, 93 84-101 (2014)

13. S. Jalili, C. Wohlin: Global Software Engineering and Agile Practices: A Systematic Review, Journal of Software Maintenance and Evolution: Research and Practice, (2011)

14. Y.I. Alzoubi, A.Q. Gill: Agile Global Software Development Communication Challenges: A Systematic Review, in: PACIS14, (2014)

15. D. Salah, R. Paige, P. Cairns: A Systematic Literature Review on Agile Development Processes and User Centred Design Integration, in: EASE14, ACM, London, (2014) 
16. T.S. da Silva, A. Martin, F. Maurer, M. Silveira: User-Centered Design and Agile Methods: A Systematic Review, in: Proceedings of AGILE, pp. 77-86 (2011)

17. E. Hossain, M.A. Babar, H. Paik: Using Scrum in Global Software Development: A Systematic Literature Review, in: International Conference on Global Software Engineering, IEEE, (2009)

18. A.J.H.d.O. Luna, P. Kuruchten, M.L.G.d.E. Pedrosa, H.R. de Almeida Neto, H.P. de Moura: State of the Art of Agile Governance: A Systematic Review, International Journal of Computer Science \& information Technology, 6 121-141 (2014)

19. M. Shen, W. Yang, G. Rong, D. Shao: Applying Agile Methods to Embedded Software Development: A Systematic Review, in: The 2nd International Workshop on Software Engineering for Embedded Systems (SEES), IEEE, Zurich, Switzerland, pp. 30-36 (2012)

20. J. Ferreira: User Experience Design and Agile Development: Integration as an On-going Achievement in Practice, in, PhD Thesis, Open University, (2011)

21. K. Dwan, D.G. Altman, J.A. Arnaiz, J. Bloom, A. Chan, E. Cronin, E. Decullier, P.J. Easterbrook, E. Von Elm, C. Gamble, D. Ghersi, J.P.A. Ioannidis, J. Simes, P.R. Williamson: Systematic Review of the Empirical Evidence of Study Publication Bias and Outcome Reporting Bias, PloS one, 3 e3081 (2008)

22. S. Freudenberg, H. Sharp: The Top 10 Burning Research Questions from Practitioners, IEEE Software, September/October 8-9 (2010)

23. T. Dingsøyr, N.B. Moe: Research Challenges in Large-Scale Agile Software Development, ACM SIGSOFT Software Engineering Notes, 38 38-39 (2013)

24. T.J. Gandomani, H. Zulzalil, A.A.A. Ghani, A.B.M. Sultan, M.Z. Nafchi: Obstacles in Moving to Agile Software Development Methods: At a Glance., Journal of Computer Science, 9 620-625 (2013)

25. G. van Waardenburg, H. van Vliet: When Agile meets the Enterprise, Information and Software Technology, 55 2154-2171 (2013)

26. K. Conboy, S. Coyle, X. Wang, M. Pikkarainen: People over Processes: Key Challenges in Agile Development, IEEE Software, 28 48-57 (2011)

27. M. Cohn, D. Ford: Introducing an Agile Process to an Organization, Computer, 36 74-78 (2003)

28. V. Braun, V. Clarke: Using Thematic Analysis in Psychology, Qualitative Research in Psychology, 3 77-101 (2006)

29. J. Eckstein: Agile Software Development in the Large: Diving into the Deep, Dorset House Publishing, New York, (2004)

30. J. Sutherland: Agile Can Scale: Inventing and Reinventing SCRUM in Five Companies, Cutter IT Journal, 14 5-11 (2001)

31. K. Conboy: Agility from First Principles: Reconstructing the Concept of Agility in Information Systems Development, Information Systems Research, 20 329-354 (2009)

32. K. Lyytinen, G.M. Rose: Information System Development Agility as Organisational Learning, European Journal of Information Systems, 15 183-199 (2006)

33. A. Janes, G. Succi: The Darker Side of Agile Software Development, in: International Symposium on New Ideas, New Paradigms, and Reflections on Programming and Software, ACM, pp. 215-228 (2012)

34. R. Hoda, J. Noble, S. Marshall: The Impact of Inadequate Customer Collaboration on SelfOrganising Agile Teams, Information and Software Technology, 53 521-534 (2011)

35. J. Brousseau: Beyond the Hype of a New Approach, in: Cutter IT Journal, Cutter Consortium, pp. 25-30 (2004)

36. J. McAvoy, T. Butler: A Failure to Learn in a Software Development Team: The Unsuccessful Introduction of an Agile Method, in: W. Wojtkowski, G. Wojtkowski, M. Lang, K. Conboy, C. Barry (Eds.) Information Systems Development: Challenges in Practice, Theory and Education, Springer US, (2010)

37. D. Avison, F. Lau, M.D. Myers, P.A. Nielsen: Action Research, Communications of the ACM, 1 94-97 (1999)

38. P. Svejvig, A.D.F. Nielsen: The Dilemma of High Level Planning in Distributed Agile Software Projects: An Action Research Study in a Danish Bank., in: Agility Across Time and Space, Springer, pp. 171-182 (2010)

39. L. Barroca, H. Sharp, D. Salah, K.J. Taylor, P. Gregory: Bridging the Gap between Research and Agile Practice: An Evolutionary Model, International Journal of Systems Assurance Engineering and Management, 6 (in press) (2015) 